\title{
WATER SECURITY FOR VILLAGE GAVHALI THROUGH ROOF TOP RAIN WATER HARVESTING
}

\author{
Pawan N. Bhavsar ${ }^{1}$, Sanjay J.Dahiwelkar ${ }^{2}$ \\ ${ }^{I}$ Professor and Head, Civil Engg Dept, JamiaCOE, Akkalkuwa MH, India \\ ${ }^{2}$ Professor and Head, Civil Engg Dept, D.N.Patel COE Shahada, MH, India
}

\begin{abstract}
The objective of this work is to compile and review the literature on Rain water harvesting, estimate the consumption of liter per capita per demand ( LPCD) for domestic and potable consumption and establish that rain water harvesting is a practical, economical and sustainable system with ecosystem specially for rural areas Fresh water is a precious and limited resource that nourishes innumerable life forms. As population pressures increase, the majority of communities around the world face the prospect decreasing supplies of fresh water in general and many would have no access to potable water at all. This lack of access impacts human health around the globe as many dies from water borne diseases and related illnesses every year.

In those communities where access to fresh water is limited and watershed health is of concern, one viable "lowtech" solution is to build a roof water harvesting system. By creating the means to store water on site, using the existing rainfall as the source and infiltrate on of the grey water and remaining run-off, one can eliminate the need to draw from precious ground water supplies and avoid the high costs (economic and environmental) of dependence on centralized conveyance and treatment systems. Humans benefit from having a self sufficient ecosystem. The ecosystem receives benefits from the reduced erosion, flooding and pollution caused by run-off and the reduction of demand on groundwater supplies.
\end{abstract}

More than $60 \%$ of Indian population lives the rural area, deforestation is the main reasons of imbalance in rainfall in every reasionof India; Satpuda is the top most range of mountain in Maharashtra which is situated on boundaries of Maharashtra Gujarat, and Maharashtra-Madhyapradesh. This part of boundary area had a thick forest cover but now-a-days the percentage of forest area has depleted. Day by day it is going on decreasing ,Adiwasi people situated along the mountain regions face the water scarcity problem, due to inadequate rainfall and ground water depletion, Gavhali villagers are face water scarcity in the month of April, May and June.

A brief methodology of the work is put forth herein; Villagers of Gavhali face water shortage during the months from April to June. The aim of this project work is to ascertain the potential of roof - top rain water harvesting for three water scarce months. Case one is to estimate per capita daily demand of water which works out to 40lpcd for three months and cost of the system. Case two is to work out the per capita daily demand of only potable water which is calculated at the 10lpcd for three months and cost of the system.

Keywords - Rain water harvesting, water scarcity

\section{INTRODUCTION}

India is a developing country. Due to faster industrialization and urbanization and increase in population water demand is increasing day by day. Rainfall in India is highly irregular. Most of it is concentrated during a few months of the year and the maximum amount flows away resulting in poor recharge of ground water. There is significant spatial imbalance in water resource availability and water demand. Therefore, it is becoming necessary to bring water from distant places increasing the cost of transport. It is also a common observation that underground water table is depleting due to uncontrolled extraction of water. The state of Maharashtra covers an area of 307,713 square $\mathrm{km}$ and supports a population of 82 million. Over half of this population is in rural area which faces shortage of water. Conventional sources such as open well, bore well and piped water supplies have failed due to depleting water tables, poor water quality and high cost involved in operation and maintenance. Every year a copies amount of water is being lost that falls on terraces, all of which finds its way to the storm water drains. Rain water harvesting can play an important role for solving the shortage of water.

Rainwater harvesting means the activity of direct collection of rain water which can recharge the ground water to prevent fall of ground water level or storing in surface or underground water tank. It is the solution of in today due to the following reasons.

1. It is the most scientific and cost effective way of recharging the ground water and reviving the water table.

2. It offers advantage in water quality for both irrigation and domestic use.

3. It provides naturally soft water and contains almost no dissolved minerals or salts, arsenic and other heavy 
metals, the only constraint of it being used as potable water is to add salts to bring it to WHO standard.

4. It can be done at individual as well as in a community level. This way we can be self sufficient in terms of domestic water requirements and not just dependent on the actions initiated by government or any other local body.

\subsection{Meaning of Roof Water Harvesting}

'Rainwater harvesting' is a widely used term covering all those techniques whereby rain is intercepted and used 'close' to where it first reaches the earth. The term has been applied to arrangements to cause rainfall to percolate in the ground rather than run off its surface, in form of flood control, by the construction of small reservoirs to capture run-off water so that it can be used for cattle or microirrigation and for the collection of run-off from roofs and other impermeable surfaces. Thus, roof water harvesting is a subset of rainwater harvesting, albeit an important one.

\section{The main objectives of the paper is}

i. To promote Rooftop rain water harvesting system in village area.

ii. To convince the community for utilization of roof - top rain water for domestic purpose.

iii. To analyze the reduction in water related problems.

\section{Study area for this paper work}

The study area falls in the Deccan plateau region of Maharashtra. It is located in the village, tribal district Nadurbar, Nadurbar district is located on the boundaries Maharashtra, Gujarat, Madhyapradesh, which on the Surat Nagpur railway line, $70 \mathrm{~km}$ away from Sardarsarovar project.

\section{Methodology for paper work}

A general village survey was carried out to assess the roof top area of individual houses along with the sociological survey. Some secondary information such as population, agriculture, climate, rainfall, number of rainy days etc. was collected from the related departments. For the analysis of primary as well as secondary data, statistical methods were used according to need.

\section{FRAMEWORK OF RTRWH FOR VILLAGE}

\section{GAVHALI}

Nandurbaris an administrative district in the northwest corner of - Khandesh Region in Maharashtra State in India. On the $1^{\text {st }}$ of July 1998 , Dhule was bifurcated in two separate districts of Dhule and Nandurbar. The district headquarters are located in Nandurbar. The district occupies an area of $5035 \mathrm{~km}^{2}$ and has a population of 1,311,709 of which $15.45 \%$ were urban (as of 2001).

\subsection{Gavhali Village}

This village is 70 kilometers away from Nandurbar town and lies on the Ankaleshwar- Barnapur road, 5 kilometers before the Sagbara border of Maharashtra State and it comes
underAkkalkuwaTaluka (District Nandurbar)on the border of Maharashtra and Gujarat. The village people are mainly belongs to Adiwasi religious. The village is situated on flat level ground. The main occupation of the Gavhali people is farming. The main crops of these peoples in farming are Crops Jawar, Wheat, Toor, Groundnuts, and Chillywhich reqiure. The village is kept neat and clean and all internal roads are made from concrete. The village has its own water supply scheme, the waste water produced from houses is discharged in soak pits, therefor it is free from mosquito infestation. Every house is of a fully detached type and has sufficient open space around it to full fill their needs of food grain storage, animal sheds, internal gardens, playing area for children and parking for vehicles. Every house has grown shade trees around it. Almost all houses are built from traditional Adiwasi housing techniques, hosing walls are made from Bamboo and Toor partitions which are plastered both inside and outside with the mud and cow dung. This creates cool internal atmosphere in the hot summer and warm atmosphere in the cool winter, Roofing materials of the house is burnt clay tiles on pitch wooden roofs. At present the total houses are 172 number, and the current population is 690 . For the water supply a total of eight numbers of stand posts are situated in different parts of village and additional sources of water are hand pumps which are seven in numbers.

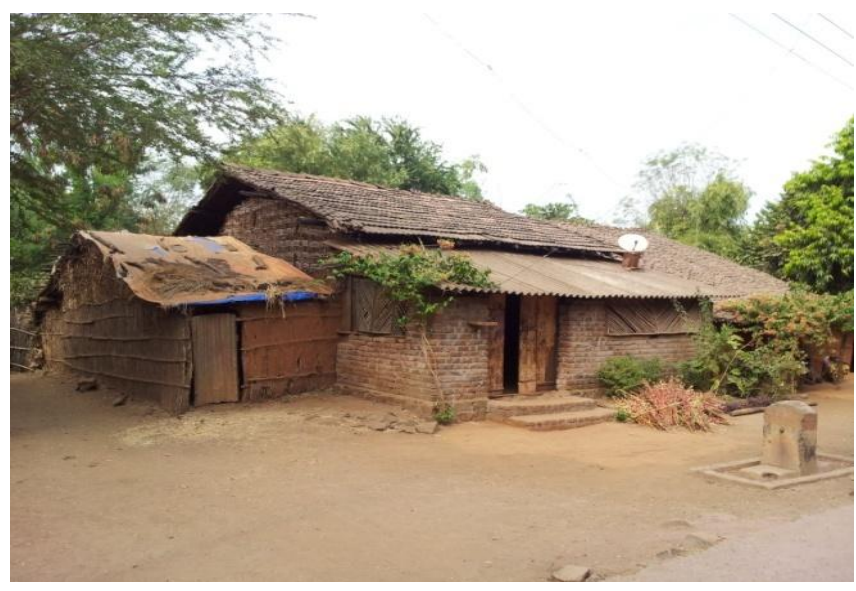

The above configuration of village with the stand post is picturised to get a better understanding of the civil facilities various shapes of the roof tops and locations of various stand post which are to be included in water supply system.

The last few years due to insufficient rainfall the village water wells and hand pumps discharge is in sufficient in the months of April, May and June. The people from the village face a water criss during this period. To fulfill their water demand, it is proposed to provide roof-top rain water harvesting scheme for the village. The village has one SwadhyayaParivar and it is the caretaker of one of the famous temples - Amrutalayam. The swadhyayaparivar helps in the village develop the overallment of the village. The roof - top rainwater harvesting project is a proposal of SwadhyayaPariwar for full filling the water demand of the village. 


\subsection{Methodology of Proposed Work}

Villagers of Gavhali face water shortage during the months from April to June. The aim of this project work is to ascertain the potential of roof - top rain water harvesting for three water scarce months. Case one is to estimate per capita daily demand of water which works out to 40lpcd for three months and cost of the system. Case two is to work out the per capita daily demand of only potable water which is calculated at the 10lpcd for three months and cost of the system.

Table 1 "Monsoon rainfall data of AkkalkuwaTaluka (years 1998-2012)"

\begin{tabular}{|l|l|l|l|l|l|l|l|}
\hline S. N & Year & Jun & Jul & Aug & Sep & Oct & $\begin{array}{l}\text { Total } \\
\text { Rainfall }\end{array}$ \\
\hline 1 & 1998 & 116 & 317 & 242 & 493 & 92 & 1260 \\
\hline 2 & 1999 & 139 & 208 & 71 & 67 & 24 & 509 \\
\hline 3 & 2000 & 170 & 249 & 111 & 44 & 1 & 575 \\
\hline 4 & 2001 & 4460 & 306 & 263 & 48 & 71 & 1134 \\
\hline 5 & 2002 & 251 & 47 & 274 & 194 & 0 & 766 \\
\hline 6 & 2003 & 394 & 298 & 289 & 49 & 0 & 1030 \\
\hline 7 & 2004 & 83 & 274 & 472 & 81 & 76 & 986 \\
\hline 8 & 2005 & 317 & 403 & 193 & 253 & 0 & 1166 \\
\hline 9 & 2006 & 236 & 670 & 610 & 222 & 12 & 1750 \\
\hline 10 & 2007 & 132 & 232 & 101 & 117 & 0 & 582 \\
\hline 11 & 2008 & 118 & 112 & 179 & 73 & 48 & 530 \\
\hline 12 & 2009 & 7 & 132 & 66 & 79 & 103 & 386 \\
\hline 13 & 2010 & 35 & 63 & 78 & 112 & 144 & 433 \\
\hline 14 & 2011 & 38 & 102 & 154 & 103 & 105 & 503 \\
\hline 15 & 2012 & 57 & 373 & 525 & 176 & 0 & 1131 \\
\hline $\begin{array}{l}\text { Total } \\
\text { Avg }\end{array}$ & & $\mathbf{1 6 9}$ & $\mathbf{2 5 2}$ & $\mathbf{2 4 2}$ & $\mathbf{1 4 1}$ & $\mathbf{4 5}$ & $\mathbf{8 4 9}$ \\
\hline
\end{tabular}

\subsection{Structure of RTRWH for Gavhali Village}

House to house survey of the Gavhali village has been carried out for working out roof area of each house and the number of accuponts of each house. Total number of houses presently is at 172 . It is observed that the roof - area varies from 25 square meters to 200 square meters maximum and it has been decided to make comparison matrixs of three types of tanks for construction cost analysis. Their are burnt brick masonry (BBM) tanks, reinforced concrete (RCC) water tanks and ferrocement water tanks, and working out the potential of ground water recharge after fulfilling the water demand for two cases i.e (Case one for their per capita daily demand of water that is 40lpcd for three months and cost of total system, Case two for their per capita daily demand of potable water that is 10lpcd for the three months and cost of the total system) and also working out the cost of all pipe network including filters for the eight different groups.

\subsection{Monsoon Rain Fall Data of Akkalkuwa Taluka}

\section{(District Nandurbar)}

The monsoon rain fall data of fifteen years (1998-2012) for AkkalkuwaTaluka (district Nandurbar) has been taken from the irrigation department. Monsoon data from June to
October has been used to find out the average annual monsoon rain rainfall for the fifteen years (1998-2012) as shown in the table no 5.1 and from this data the potential of roof - top rain water harvesting for 172 villages has been worked out.

Sourc-Irrigation departmentNandurbar

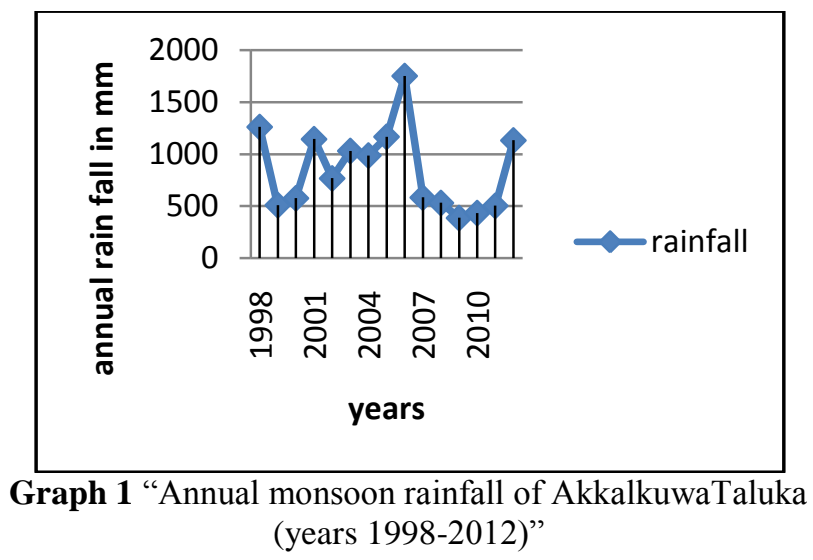

Graph no1 shows the annual monsoon rainfall of years (1998-2012), it's clear that maximum rainfall has occurred in the year 2006 and the minimum rainfall occurred in the year 2009. From year 2001 up to 2006, the rain fall was more than the average annual monsoon rain fall the last years, but from 2007 up to 2011 the rain fall was nearly half of the annual monsoon rain fall the last years. It is clearly shown in the figure that the last six years except 2012, the rain fall was very poor, this was the main reason of the ground water table lavel falling in Gavhali village. Natural recharging of ground water table was nearly half of the annual rain fall, this is the main reason that the villagers are currently facing a water scarcity in the last five six years .

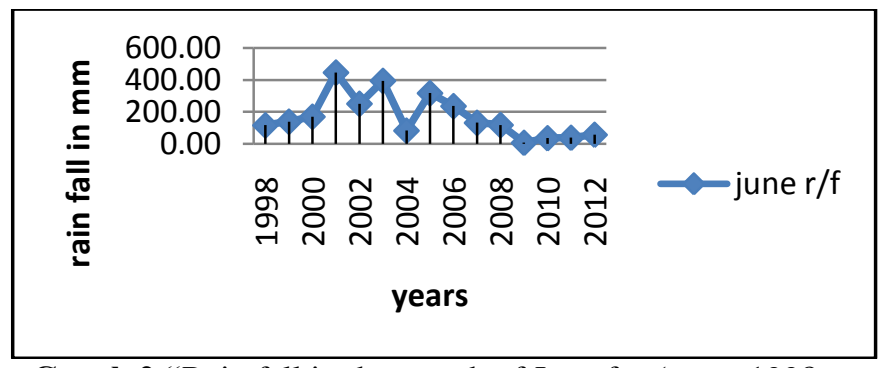

Graph 2 "Rain fall in the month of June for (years 19982012)"

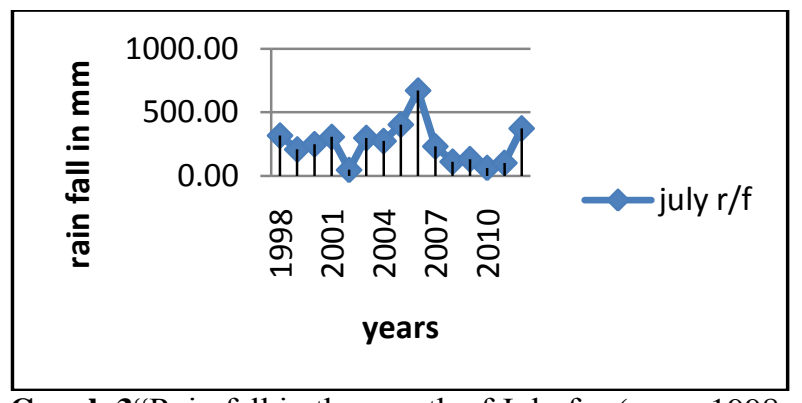

Graph 3"Rain fall in the month of July for (years 19982012)" 


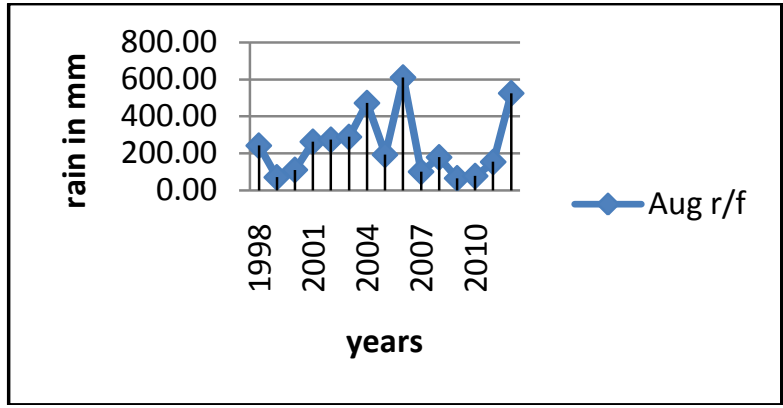

Graph 4 "Rain fall in the month of August for (years 19982012)"

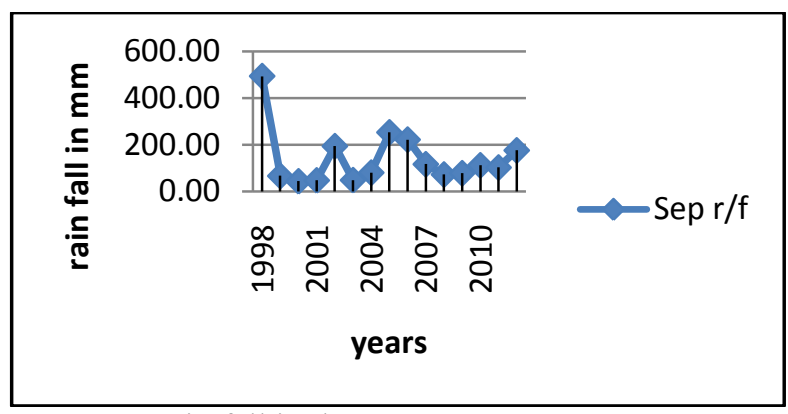

Graph 5"Rain fall in the month of September for (years 1998-2012)"

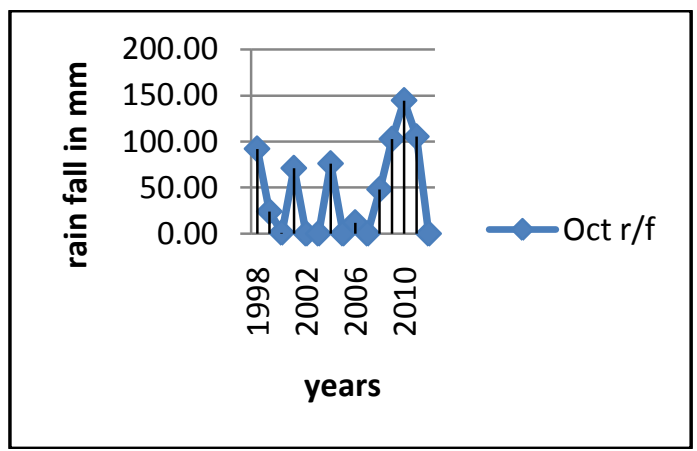

Graph 6 "Rain fall in the month of October for (years 19982012)"

Graphno 2,3,4,5,6 shows each of the monsoon month's rain fall that has occurred in the last 15 years (1998-2015). From all these figures it is clear that the maximum monsoon rain fall has occurred in the month of July and August and the minimum rain fall has occurred in the month of October, September and July.

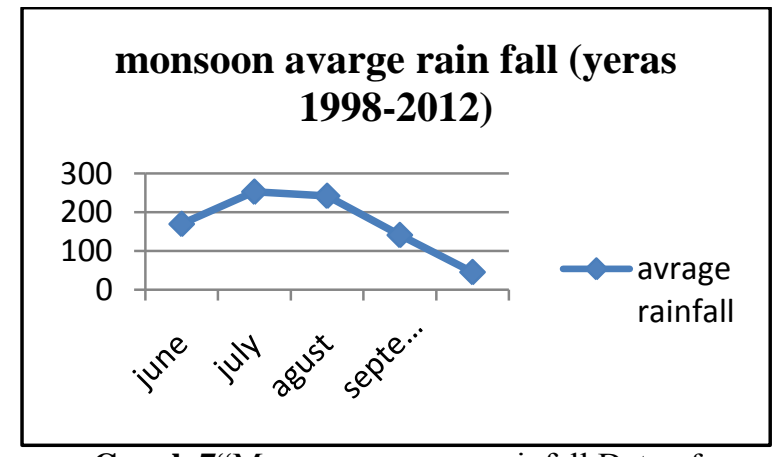

Graph 7"Monsoon average rainfall Data of AkkalkuwaTaluka (years 1998-2012)"

\subsection{Assumptions for Design and Cost Estimation of}

\section{Roof - Top Rainwater Harvesting for Village}

a) Rain fall intensity is taken at $50 \mathrm{~mm}$ /hour from the map instead of practical estimation in Nandurbar region.

b) The sizes of vertical rain water pvc pipes are extrapolated from the table given in BIS: 17421983. and The American Institute of plumbing engineering AIPE formula.

c) Runoff coefficient is considered as 0.75 for tiled roof. As mention in table no 4.2 in chapter no 4

d) Diameter of vertical down pipe is considered as $100 \mathrm{~mm}$ for rain fall intensity $50 \mathrm{~mm} /$ hour

\subsection{Procedure of finding out Potential of Roof - Top}

\section{Rain Water Harvesting}

\subsubsection{Case A) Procedure of finding out Potential of} Roof - Top Rain Water Harvesting for the Per

\section{Capita Daily Demand of Water that is $40 \mathrm{Lpcd}$.}

The village has one hundred and seventy two building structures; every structure is unique, and has different roof top area, different number of users, different water demand and different roof - top water harvesting potential. The per capita daily demand for house no 11 for the village, is calculated as following as an exampls, randomly releated from 172 houses.

House number- 11

Name of the owner - AmryaSamyaGavit

No family members - 5 numbers

Daily demand - $\quad 40$ lpcd

Water scare months - three months (April, May, June)

Roof - top area - 48 meters square

Daily demand calculation - 5 (no of persons) X $40 \mathrm{lpcd}$ (water demand in liters) $=200 \mathrm{lpcd}$.

Annual monsoon water harvesting potential $=$ roof area $\mathrm{x}$ runoff coefficient $\mathrm{x}$ average rainfall

$=48 \times 0.75 \times 0.849$

= 30.576 meter cube $(30,576$ liters $)$.

Water demand for three water scare months = daily demand $\mathrm{x}$ no days

$=200 \times 91$

$=\mathbf{1 8 , 2 0 0}$ liters.

Ground water recharge capacity $=($ Annual monsoon water harvesting potential -Water demand for three water scare months)

$$
\begin{aligned}
& =30,576-18,200 \\
& =\mathbf{1 2 , 3 7 6} \text { liters. }
\end{aligned}
$$

It is considered to store the water to be harvested for water scare months. The materials for the water tanks are selected as reinforced cement concrete (R.C.C), brunt brick masonry 
(B.B.M.), Ferro cement and the cost of different water tanks are calculated as for the case $\mathbf{A}$ as follows.

Reinforced cement concrete water tank Rs.81,600

Brunt brick masonry water tank Rs.74,100

Ferro cement water tank Rs.55,100

\subsubsection{Case B) Procedure of Finding out Potential of}

Roof - Top Rain Water Harvesting for the Per

Capita Daily Demand of Potable Water that is $\mathbf{1 0}$

\section{Lped}

The per capita daily demand for house no 11 for the village, is calculated as following as an examples, randomly related from 172 houses.

House number- 11

Name of the owner- AmryaSamyaGavit

No family members- 5 numbers

Daily demand - 10 lpcd

Water scare months - three months (April, May, June)

Roof - top area- 48 meters square

Daily demand calculation $=5$ (no of persons) $X 10 \mathrm{lpcd}$ (water demand in liters) $=50 \mathrm{lpcd}$.

Annual monsoon water harvesting potential $=$ roof area $\mathrm{x}$ runoff coefficient $\mathrm{x}$ average rainfall $=48 \times 0.75 \times 0.849$ = 30.576 meter cube $(30,576$ liters $)$.

Water demand for three water scare months = daily demand $\mathrm{x}$ no days $=50 \times 91=\mathbf{4 , 5 5 0}$ liters.

Ground water recharge capacity $=$ (Annual monsoon water harvesting potential Water demand for te water scare months)

$$
\begin{aligned}
& =30,576-4,550 \\
& =\mathbf{2 6 , 0 2 6} \text { liters. }
\end{aligned}
$$

Costs of different water tanks are calculated as for the case $\mathbf{B}$ are followings.

Reinforced cement concrete water tank Rs. 20,400

Brunt brick masonry water tank Rs.18,600

Ferro cement water tank Rs.13,700

From the above observations of cases $\mathbf{A}$ and $\mathbf{B}$ the daily demand, water demand for three water scare months, ground water recharge capacity and costs of different water tanks have been calculated based on all these parameters taking into consideration the different annual monsoon water harvesting potential on the basis of the roof area and average rainfall which is the same in both cases.

\section{CONCLUSIONS}

- Deforestation is the main reasons of imbalance in rainfall in every part of India; Satpuda is the top most range of mountains in Maharashtra which is situated on the boundaries of Maharashtra-Gujarat,
Maharashtra- Madhyapradesh. This part of the boundary area had thick forest, but now-a-days the percentage of forest area has reduced drastically and is going on decreasing on basis day to day. Adiwasi people situated along this mountain regions are facing a water scarcity problem, due to inadequate rainfall and ground water depletion. Gavhali villagers are facing water scarcity in the months of April, May and June.

- The project work done is a part solution for the problem of water scarcity for the village in the summer seasons, on request of the villagers for roof - top water harvesting for 172 houses.

- It is clearly found from the graph of annual monsoon rainfall of AkkalkuwaTaluka (years 19982012). Year 2001 up to 2006 the rain fall was nearly more than annual monsoon rain fall of 15 years, but from 2007 up to 2011 the rain fall was nearly half of the annual monsoon rain fall of 15 years, it's clearly shown in the graph that last six years except 2012 the rain fall was very poor, this was the main reason of lowering down the ground water table of Gavhali village it shown in the graph.

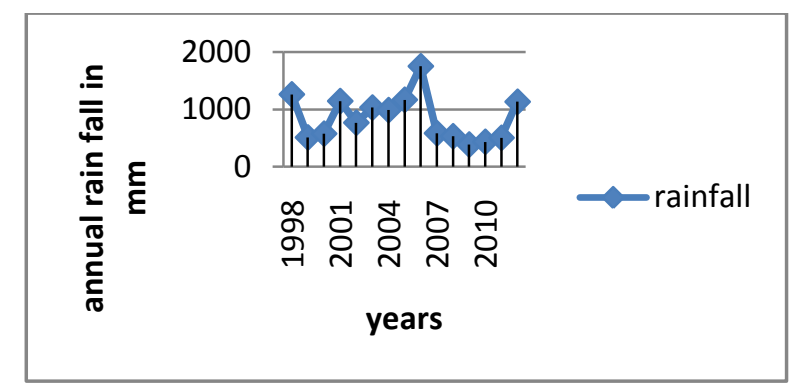

Graph 8 "Annual monsoon rainfall of AkkalkuwaTaluka (years 1998-2012)"

- In this project work is to ascertain the potential of roof - top rain water harvesting for three water scarce months. Case one is to estimate per capita daily demand of water which works out to 40lpcd for three months and cost of the system. Case two is to work out the per capita daily demand of only potable water which is calculated at the 10lpcd for three months and cost of the system.

- A random house from the total 172 house, house number 11 was selected and calculations are made for case number oneand case number two. For Case No.1 has been based on the parameter of demand of $40 \mathrm{lpcd}$ for house No. 11. The monsoon roof - top water harvesting potential is 30,576 liters. Water demand for three water scare months was estimated at $\mathbf{1 8 2 0 0}$ liters. Ground water recharge capacity is $\mathbf{1 2 3 7 6}$ liters. andcost of water tanks are, R.C.C tankRs. 81600/- B.B.M tank Rs. 74100/- and ferrocement tankRs. 55100/-

- For Case No.1 has been based on the parameter of demand of 10ped for house No. 11. The monsoon roof - top water harvesting potential is 4550 liters. Therefore excess water for ground water recharge is $\mathbf{2 6 , 0 2 6}$ liters . Cost of water tanks for $10 \mathrm{lpcd}$ are 
R.C.C tankRs. 20,400/- B.B.M tankRs. 18600 and ferrocement tankRs. 13700/-

Followings graphs 6.2 and 6 . shows the cost of tanks in ruppies for case number one (demand 40 liter/capita/day) and case number two (demand 10 liter/capita/day)

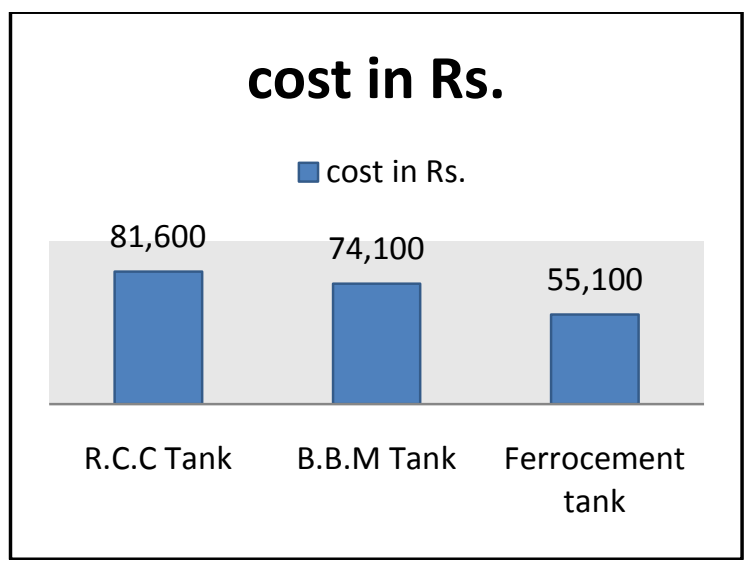

Graph 9 "Cost of water tanks for case number one (demand 40 liter/capita/day)"

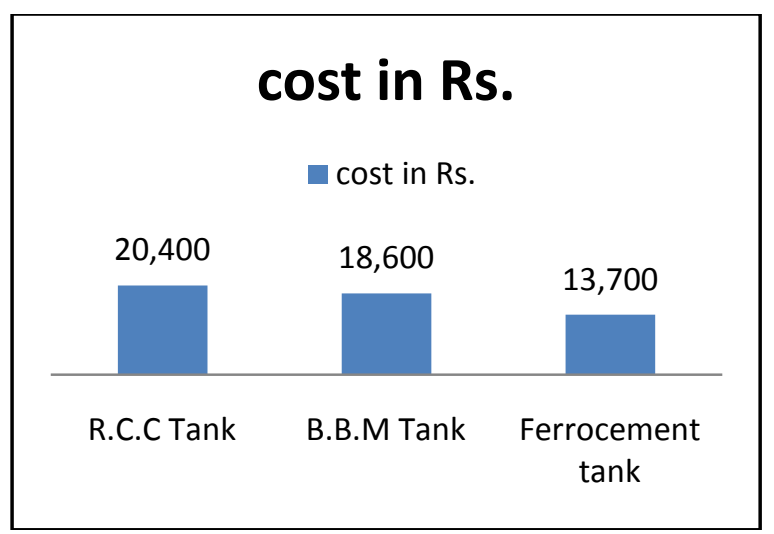

Graph 10 "Cost of water tanks for case number two (demand 10 liter/capita/day)"

Following graph 11 shows the possible ground water recharge for case number one (demand 40 liter/capita/day) and case number two (demand 10 liter/capita/day).

\section{Ground Water Recharge in Liters}

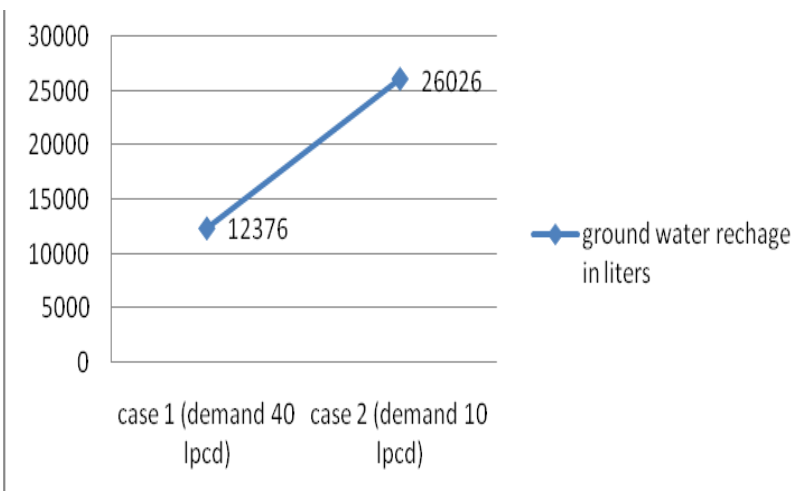

Graph 11 "case 1 (demand 40 liter/capita/day) and case 2(demand 10 liter/capita/day)"
From the above study it is found that the roof - top rain water harvesting is the most reliable and cost effective solution for the village Gavhali for both the purposes i.e. demand of water during the water scacre months and ground water recharging.

- The project work done is complete cost effective solution in not only fulfilling the demand but also replenish the ground water table.

\subsection{Limitations}

- Incase storage tank not adequately covered then mosquitoes larvae can cause death due to dengue.

- The roof water harvesting is not advisable to be used for long period as potable water due to lack of calcium magnesium fluorite etc.

\subsection{Future Scope of The Work}

- $\quad$ Future scope of this work is detailed investigation of depleted ground water table and detailed methods, cost estimates of ground water recharging structures and calculation of how much ground water recharge is possible for Gavhali village.

- Actual practical estimation of rainfall intencity on the field.

- Forecasting the Village population growth and planning for future rain water harvesting and water table recharging projects in a cost effective method.

\section{REFERENCES}

[1] GUIDANCE ON USE OF RAINWATER TANKS, RAINWATER HARVESTING: A LIFELINE FOR HUMAN WELL-BEING A report prepared for UNEP by Stockholm Environment Institute.Rainwater Harvesting - UNEP ISBN: 978 92 - 807 - 3019 - 7 Job No. DEP/1162/NA.

[2] Rainwater harvesting for domestic use , First edition: 2006 Authors: Janette Worm, Tim van Hattum Illustrators: Liesbeth Worm, BarberaOranje Design: Eva Kok,Translation: Catherina de KatReynen (editing)'Printed by: Digigrafi, Wageningen, the Neteherlands,ISBNAgromisa: 90-8573-0538,ISBN CTA: 92-9081-330-X.

[3] Roofwaterharvesting,Thomas, T.H. and Martinson, D.B. (2007). Roofwater Harvesting: A Handbook for Practitioners. Delft, the Netherlands, IRC International Water and Sanitation Centre.(Technical Paper Series; no. 49).160 p.

[4] Roofwater harvesting and water supply of Ngalamye village, Uganda.

\section{BIOGRAPHIES}

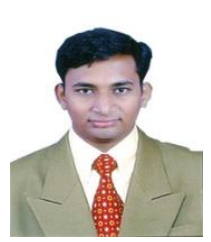

Pawan N Bhavsar, H.O.D. and Asst Professor, Jamia College of Engineering Akkalkuwa. Nandurbar, Mob 9890056261 
Sanjay J Dahiwelkar, H.O.D. and Asst.

Professor, D.N.Patel College of

Engineering, Shahada, Nandurbar, Mob 9423194675 